\title{
Birth prevalence of congenital heart defects: A five and a half year study in a teaching hospital in Sri Lanka
}

\author{
*CR Gunaratne ${ }^{1}$, KSY Perera ${ }^{2}$, Medha Weerasekera ${ }^{3}$
}

Sri Lanka Journal of Child Health, 2022; 51(1): 46-51

DOI: http://dx.doi.org/10.4038/sljch.v51i1.9991

\begin{abstract}
Introduction: Congenital heart defect (CHD) is the commonest congenital anomaly, accounting for $28 \%$ of major malformations. Birth prevalence of CHDs ranges from 5-10 per 1000 live births.
\end{abstract}

Objectives: To assess the birth prevalence of CHDs and describe the structural variations, severity and prevalence among different birth weights.

Method: This is a hospital based retrospective study over a period of $5 \frac{1}{2}$ years from $01 / 01 / 2015$ to $30 / 06 / 2020$. All live births at the Sri Jayewardenepura General Hospital (SJGH) during the study period were included in the study. Data were extracted from the congenital birth defects registry, maintained by the medical staff of the neonatal unit of SJGH since 2015. Data were entered into Excel sheet and analysed using SPSS statistical software version 22 .

Results: A total of 19,729 babies was born during the study period. Prevalence was 13.64 per 1000 live births. Prevalence of mild, moderate and severe cases were $8 / 1000,2.73 / 1000$ and $2.69 / 1000$ live births respectively. Prevalence of CHDs in low birth weight (LBW) and normal birth weight babies were 42.54 and 8.9 per 1000 live births respectively. Atrial septal defect (ASD) was the most prevalent heart defect followed by patent ductus arteriosus (PDA) and ventricular septal defect (VSD). Tetralogy of Fallot (TOF) was the most prevalent critical congenital heart defect (CCHD). Right ventricular tract obstructive lesions were more prevalent than left ventricular tract obstructive lesions.

${ }^{1}$ Senior Registrar in Neonatology, ${ }^{2}$ Medical Officer,
${ }^{3}$ Consultant Neonatologist, Neonatal Unit, Sri
Jayewardenepura General Hospital, Kotte, Sri
Lanka
*Correspondence: mail2roshii@yahoo.com
iD. https//orcid.org/0000-0002-0798-1986 (Received on 29 January 2021: Accepted after revision on 19 March 2021)

The authors declare that there are no conflicts of interest

Personal funding was used for the project.

Open Access Article published under the Creative

Commons Attribution CC-BY@c) (i) License
Conclusions: CHD prevalence in this hospital based study was 13.64 per 1000 live births. ASD was the most prevalent CHD with PDA and VSD recording second and third places respectively. TOF was the most prevalent CCHD. Pulmonary outflow tract obstructive lesions were more prevalent than left ventricular outflow tract lesions. CHD prevalence was significantly higher in LBW babies than in normal birth weight babies.

(Key words: Congenital heart defects, Birth prevalence)

\section{Introduction}

Congenital heart defects (CHDs) are the commonest congenital anomalies, accounting for $28 \%$ of all major malformations ${ }^{1-5}$. They are responsible for 6$10 \%$ of all infant deaths and $20-40 \%$ of deaths due to congenital malformations ${ }^{6-9}$. Thus, CHD has become the leading cause of infant mortality attributable to birth defects ${ }^{4,5,7,10}$. A CHD is defined as a "structural abnormality of the heart and/or intra-thoracic great vessels present at birth, that is actually or potentially of functional significance"1,2,4,11-13. Birth prevalence of CHDs varies widely among studies worldwide. It is estimated to range between $5-10$ per 1000 live births and the estimate of 8 per 1,000 live births is generally accepted as the best approximation ${ }^{1,5,8,13-17}$. Improved postnatal detection of trivial/mild CHDs has contributed to the increased total prevalence exponentially, owing to the advancement in the ability to detect $\mathrm{CHDs}^{2}$. Significant geographical differences are noted in the birth prevalence of CHDs, with the highest prevalence in Asia (9.3 per 1,000 live births), followed by Europe (8.2 per 1,000 live births) and the lowest in Africa (1.9 per 1,000 live births $)^{1,2}$. Classifications of CHD is based on the presence/absence of cyanosis, the structural abnormality, the blood flow inside the heart, or the severity of the condition ${ }^{3,4}$. Categorization of CHD based on severity consists of three basic types mild, moderate and severe ${ }^{3,11}$. Critical congenital heart defects (CCHDs) is a subgroup within severe CHDs, characterized by lesions requiring surgery or catheter-based intervention in the first year of life or causing significant morbidity and mortality in the first weeks of life ${ }^{8}$. Table 1 shows the classification of CHDs based on severity. 
Table 1: Classification of congenital heart defects (CHDs) based on severity ${ }^{3,11}$

\begin{tabular}{|l|l|l|}
\hline \multicolumn{1}{|c|}{ Severe CHD } & \multicolumn{1}{c|}{ Moderate CHD } & \multicolumn{1}{c|}{ Mild CHD } \\
\hline All cyanotic CHDs & Mild to moderate AS and AI & Small VSD \\
\hline Atrio-ventricular canal (AVC) defects & Moderate PS & Small PDA \\
\hline Large ventricular septal defect (VSD) & Non-critical COA & Small ASD \\
\hline Large patent ductus arteriosus (PDA) & Large ASD & Mild PS \\
\hline Severe aortic stenosis (AS) & Complex VSD & BAV without AS or AI \\
\hline Severe pulmonary stenosis (PS) & & \\
\hline Critical coarctation of the aorta (COA) & & \\
\hline
\end{tabular}

AI: aortic insufficiency, BAV: bicuspid aortic valve

Reported birth prevalence of CHD worldwide has increased substantially over the past century, increasing from 0.6 per 1,000 live births in early 1930 s to 9.1 per 1,000 live births from 1995 onwards, thus representing a major global health burden ${ }^{1,2,4,11}$. However, in the last 15 years birth prevalence has remained around 1.35 million per year. The increase in reported prevalence may be a result of technological advances in screening and diagnosis rather than a true increase ${ }^{1,2,11,18,19}$.

The incidence of severe CHDs is about 2.5 to $3 / 1,000$ live births ${ }^{1,5,11}$. Moderately severe forms of CHDs account for another 3 per 1,000 live births ${ }^{11,17}$, resulting in a total prevalence of moderate and severe forms of lesions at $6 / 1000$ live births ${ }^{1,11}$. Out of all CHDs, ventricular septal defect (VSD) has the highest reported birth prevalence worldwide (2.62 per 1,000 live births $)^{1,4,11,17}$. The birth prevalence of pulmonary outflow obstructions shows an increasing trend as opposed to left ventricular outflow obstructive lesions since 1995 onwards $^{2}$. However, significant geographical differences were reported on birth prevalence of right and left obstructive lesions; as Asia reported relatively more pulmonary outflow obstructions and fewer left ventricular outflow tract obstructions, and transposition of great arteries (TGA) compared to Europe, North America, South America, and Oceania ${ }^{1,6,7,11}$.

Though there are studies done in the past, showing varying incidence over years as well as geographical variations, not many studies have been carried out in developing countries in the recent past. With the introduction of "pulse oximetry screening" as part of newborn screening prior to discharge from hospital, a definite increase in reported incidence of severe CHD is expected. It is timely that a study of this nature is carried out in Sri Lanka.

\section{General objective}

To assess the birth prevalence of CHDs at Sri Jayewardenepura General Hospital (SJGH), Sri Lanka.

\section{Specific objectives}

1. To estimate the birth prevalence of CHD according to severity.

2. To identify the birth prevalence of different types of CHDs.

3. To assess the prevalence of CHDs among different birth weight groups.

Method

Design and study population: A hospital based retrospective study was conducted over a period of $5 \frac{1}{2}$ years from $01 / 01 / 2015$ to $30 / 06 / 2020$. Data were extracted from the congenital birth defects registry, maintained by the medical staff of the neonatal unit of SJGH since 2015. All live born well babies in postnatal wards, as well as sick babies at the neonatal unit of SJGH, with either abnormal clinical cardiac examination at routine newborn examination or with low oxygen saturation as per PO test, were referred to a paediatric cardiologist at Lady Ridgeway Hospital for Children (LRH) for comprehensive 2D echocardiography (2D echo) and the babies with abnormal $2 \mathrm{D}$ echo findings were entered into the registry.

Setting: Sri Jayewardenepura General Hospital, which is a tertiary care centre providing level 3 neonatal care in Sri Lanka.

Statistical analysis: Data were entered into Excel sheet and analysed using SPSS statistical software version 22. No specific statistical test or significance level were used as we have not compared the data but calculated the prevalence of each category.

Ethical issues: Ethical clearance has been obtained from the Ethics Review Committee of Sri Jayawardenepura General Hospital and Postgraduate Training Centre, Nugegoda, Sri Lanka on $26 / 08 / 2020$. As it was a retrospective study, informed consent was not possible. Confidentiality of data is assured. 


\section{Results}

Total births during the study period was 19,729 (Table 2). Live birth rates were similar from 20152019 with slight reduction in 2020, most likely due to the COVID-19 situation driving more mothers to deliver at private hospitals, avoiding crowded government institutions. A total of 271 were confirmed as having CHDs. Birth prevalence of CHDs was quite similar during the last $4 \frac{1}{2}$ year period with the exception of 2015, where a substantially reduced CHD birth prevalence was recorded. Average birth prevalence of CHD over the study period was 13.74 per 1000 live births (Table 2).

Distribution of critical congenital heart defects (CCHDs) according to primary diagnosis over the study period is shown in Table 3 .

Table 2: Birth prevalence of congenital heart defects (CHD) during the study period

\begin{tabular}{|l|c|c|c|c|c|c|c|}
\hline \multicolumn{1}{|c|}{ Year } & $\mathbf{2 0 1 5}$ & $\mathbf{2 0 1 6}$ & $\mathbf{2 0 1 7}$ & $\mathbf{2 0 1 8}$ & $\mathbf{2 0 1 9}$ & $\begin{array}{l}\mathbf{2 0 2 0} \text { up } \\
\text { to June }\end{array}$ & $\begin{array}{l}\text { Over study } \\
\text { period }\end{array}$ \\
\hline No of Live Births & 3627 & 3611 & 3758 & 3609 & 3471 & 1653 & 19,279 \\
\hline No of CHDs & 30 & 58 & 53 & 61 & 48 & 21 & 271 \\
\hline Birth prevalence of CHD per 1000 live births & 8.27 & 16.06 & 14.10 & 16.90 & 13.82 & 12.70 & 13.74 \\
\hline
\end{tabular}

Table 3: Distribution of critical congenital heart defects (CCHDs) according to primary diagnosis over the study period

\begin{tabular}{|l|c|c|c|c|c|c|c|c|}
\hline \multicolumn{1}{|c|}{ Type of lesion } & $\mathbf{2 0 1 5}$ & $\mathbf{2 0 1 6}$ & $\mathbf{2 0 1 7}$ & $\mathbf{2 0 1 8}$ & $\mathbf{2 0 1 9}$ & $\mathbf{2 0 2 0}$ till June & Total & Prevalence \\
\hline Tetralogy of Fallot & 02 & - & 01 & 04 & 01 & 01 & 09 & $0.46 / 10^{3}$ \\
\hline Hypoplastic left heart & - & - & - & 01 & 03 & - & 04 & $0.2 / 10^{3}$ \\
\hline Transposition of great arteries & 01 & 01 & - & - & 01 & - & 03 & $0.15 / 10^{3}$ \\
\hline Pulmonary atresia & - & 01 & 02 & - & - & - & 03 & $0.15 / 10^{3}$ \\
\hline TAPVD & - & - & 01 & - & 01 & - & 02 & $0.1 / 10^{3}$ \\
\hline Tricuspid atresia & 01 & - & - & - & - & 01 & 02 & $0.1 / 10^{3}$ \\
\hline Univentricular heart & 01 & 01 & - & - & - & - & 02 & $0.1 / 10^{3}$ \\
\hline Truncus arteriosus & - & - & - & - & 01 & - & 01 & $0.05 / 10^{3}$ \\
\hline Ebstein Anomaly & - & - & - & - & 01 & - & 01 & $0.05 / 10^{3}$ \\
\hline Total CCHDs & 05 & 03 & 04 & 05 & 08 & 02 & 27 & $13.7 / 10^{3}$ \\
\hline
\end{tabular}

TAPVD: Total Anomalous Pulmonary Venous Drainage

In terms of severity of CHDs, mild cases predominated throughout the study period with a total of 160 and a prevalence of 8.11 per 1000 live births. Moderate and severe disease showed a fluctuating prevalence through the study period. The prevalence of moderate and severe CHD was $2.73 / 10^{3}(n=56)$ and $2.69 / 10^{3}(n=55)$ respectively with a cumulative prevalence of $5.5 / 1000$ live births (Figure 1).

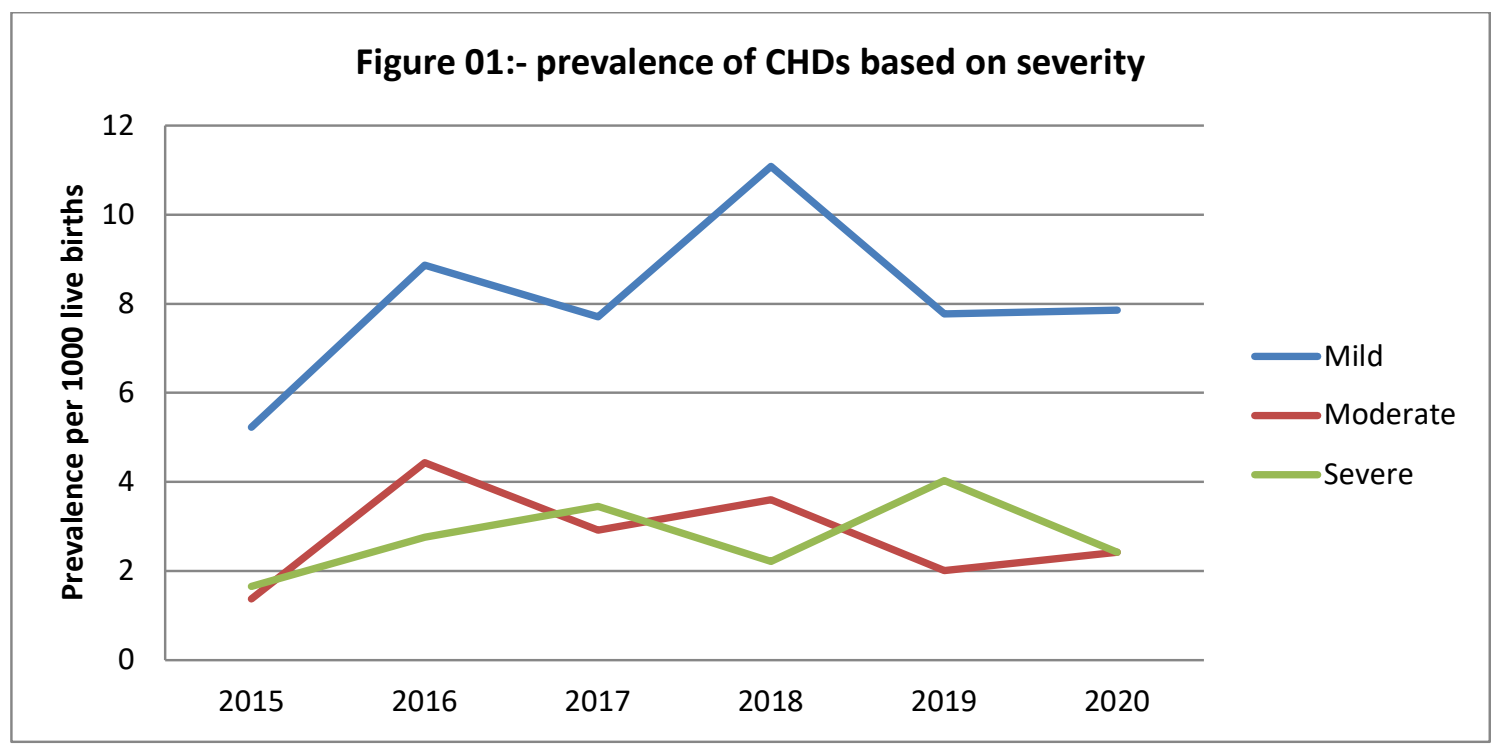

Out of 19,729 babies born over the study period, 16,908 babies had a birth weight of $\geq 2500 \mathrm{~g}$ and 151 were diagnosed with CHD while 2821 had birth weight $<2500 \mathrm{~g}$ out of which 120 were diagnosed as 
Birth prevalence of congenital heart defects: A five and ... Sri Lanka Journal of Child Health, 2022; 51(1): 46-51

CHD. This gives a CHD prevalence of 8.9/1000 live births and 42.54/1000 live births in the satisfactory birth weight and low birth weight groups respectively. In terms of individual heart lesions, atrial septal defect (ASD) showed the highest prevalence of 9.8/1000 live births, followed by patent ductus arteriosus (PDA) with a prevalence of 5.8/1000 live births and VSD with a prevalence of $2.08 / 1000$ live births.

Within the severe CHD category, a total of 27 CCHDs were confirmed over the study period giving a prevalence of $1.37 / 1000$ live births. Tetralogy of Fallot (TOF) was the commonest and showed the highest prevalence $(0.46 / 1000$ live births) followed by hypoplastic left heart (HLH) $(0.2 / 1000$ live births), TGA (0.15/1000 live births) and pulmonary atresia (PA) (0.15/1000 live births). In the CCHD group, there was a total of 12 right ventricular outflow tract obstructions (RVOTOs) compared to 4 left ventricular outflow tract obstructions (LVOTOs).

\section{Discussion}

In our study, the total CHD prevalence was high at 13.74 per 1000 live births in contrast to the Asian prevalence of $9.3 / 1000$ and average world prevalence of $8 / 1000$ live births $s^{1,5,8,13-17}$. The last $4 \frac{1}{2}$ years of our study, shows a significant increase in the yearly prevalence compared to the initial year (2015), which is most likely due to the increased detection rate rather than an increment in true prevalence as mentioned in the study by Liu Y, et al in $2019^{2}$. It is of interest that CCHD prevalence of $0.46 / 1000$ in the first 33 months has doubled over the last 33 months $(0.91 / 1000$ live births), which clearly emphasizes the benefit of compulsory pulse oximetry screening as part of neonatal screening being introduced into the Sri Lanka guidelines. With regard to the severity, mild lesions predominated as shown in other studies and recorded a mean prevalence of 8.11/1000 live births, which was not subjected to estimation in previous studies. Prevalence of moderate CHDs $(2.73 / 1000$ live births) was close to the world prevalence and severe CHDs showed similar prevalence to the studies done in other centres ${ }^{1,5,11,17}$. Prevalence of cumulative moderate and severe CHDs in our study was similar to other studies ${ }^{1,11}$. However, the overall prevalence of CCHD in our study $(1.35 / 1000$ live births) was compatible with worldwide studies which showed CCHD prevalence of 1-2/1000 live births $1,5,8,13$.

With regard to prevalence of acyanotic heart lesions, our study showed a predominance of ASD prevalence of 9.75 per 1000 live births in contrast to other studies in which VSD was the most prevalent lesion $^{1,4,11,17}$. However, prevalence of VSD secured third place in our study with a mean prevalence 1.99 / 1000 live births compared to a higher prevalence of
$2.62 / 1000$ live births in other studies. Out of cyanotic heart diseases, our study showed the high prevalence of tetralogy of Fallot (TOF) which accounted for $33 \%$ of all cyanotic CHDs compatible to other studies ${ }^{1-3}$. Even though worldwide studies have shown reduced prevalence of TGA in Asia ${ }^{1,6,7,11}$, it was estimated as the third highest prevalent cyanotic CHDs in our study, accounting for $11 \%$ out of all cyanotic CHDs. However, confirming the statements made by other global studies $1,6,7,11$, our study has shown less LVOTOs which were only 4 , compared to 12 RVOTOs over the study period. In terms of occurrence of CHDs related to birth weight, a significantly high prevalence was noted in the LBW group when compared to the normal birth weight newborns. Detection of CCHD and hence the prevalence, has increased significantly after the introduction of compulsory pulse oximetry screening test prior to discharge from hospital. However, in order to estimate the island wide prevalence of CHDs alongside the prevalence according to the severity, presence of cyanosis and the birth weight, further multicentre, large scale studies are required. In future, CHDs need to be further studied and population wide prospective birth defect registries covering the entire Sri Lankan population should be analysed to determine the exact birth prevalence in Sri Lanka.

The study had some limitations. 2D echocardiography, which is the gold standard test for the diagnosis of CHDs, was not done in all 19,729 live births during the study period, but only in newborns with abnormal cardiovascular system examination or positive PO. This was done with the intention of avoiding overburdening the paediatric cardiologists at LRH. Thus, some of the asymptomatic babies with minor CHDs might have been missed

\section{Conclusions}

CHD prevalence in this hospital based study was 13.64 per 1000 live births. ASD was the most prevalent $\mathrm{CHD}$ with PDA and VSD recording second and third places respectively. TOF was the most prevalent CCHD. Pulmonary outflow tract obstructive lesions were more prevalent than left ventricular outflow tract lesions. CHD prevalence was significantly higher in LBW babies than in normal birth weight babies.

\section{Acknowledgement}

We thank the medical staff in the neonatal unit$\mathrm{SJGH}$, for the clear and diligent documentation of every fine detail of babies with congenital anomalies including 2D echocardiogram findings over such a long period. We are equally grateful to all the parents and their babies without whom this research would not have been a reality. 


\section{References}

1. Linde DVD, Konings EEM, Slager MA, Witsenburg M, Helbing WA, Takkenburg JJM, et al. Birth prevalence of congenital heart disease worldwide: A systemic review and meta-analysis. American Journal of Cardiology 2011; 58: 2241-7.

https://doi.org/10.1016/j.jacc.2011.08.025

PMid: 22078432

2. Liu Y, Chen S, Zuhjke L, Black GC, Choy $\mathrm{M}-\mathrm{K}$, Li N, et al. Global birth prevalence of congenital heart defects 1970-2017: Updated systematic review and metaanalysis. International Journal of Epidemiology 2019; 48(2): 455-63. https://doi.org/10.1093/ije/dyz009

PMid: 30783674 PMCid: PMC6469300

3. AL-Ammouri I, Ayoub F, Tutunji L. Incidence of congenital heart disease in Jordanian children born at Jordan University Hospital; a seven-year retrospective study. Jordanian Medical Journal 2017; 51(3): 109-17.

4. Aljohani AA, Wedad SA. Incidence of congenital heart disease: A 10-year incidence meta-analysis and systematic review of the importance of neonatal screening. EC Paediatrics 2019; 8(9): 94872 .

5. Majeed-Saidan MA, Atiyah M, Amman AN, AlHashem AM, Rakaf MS, Shoukri MM, et al. Patterns, prevalence, risk factors, and survival of newborns with congenital heart defects in a Saudi population: a threeyear, cohort case-control study. Journal of Congenital Cardiology 2019; 3(2): 1-10. https://doi.org/10.1186/s40949-019-0023-8

6. Garnelli A deW, Wennergren M, Sandberg $\mathrm{K}$, Mellander M, Bejlum C, Inganas L, et al. Impact of pulse oximetry screening on the detection of duct dependent congenital heart disease: a Swedish prospective screening study in 39821 newborns. BMJ 2009; 338: 3037-45.

https://doi.org/10.1136/bmj.a3037

PMid: 19131383 PMCid: PMC2627280

7. Thangaratinam S, Brown K, Zamora J, Khan KS, Ewere EK. Pulse oximetry screening for critical congenital heart defects in asymptomatic newborn babies: a systemic review and meta-analysis. Lancet 2012; 379(9835): 2459-64.
https://doi.org/10.1016/S01406736(12)601

$07-\mathrm{X}$

8. Frank LH, Bradshaw E, Beekman R, Mahle WT, Martin GR. Critical congenital heart disease screening using pulse oximetry. Journal of Paediatrics 2013; 162(3): 44553.

https://doi.org/10.1016/j.jpeds.2012.11.020

PMid: 23266220

9. Abu-Harb M, En H, Wren C. Death in infancy from unrecognised congenital heart disease. Archives of Disease in Childhood 1994; 71(1): 3-7. https://doi.org/10.1136/adc.71.1.3

PMid: 8067789 PMCid: PMC1029901

10. Ewer AK, Middleton LJ, Furmston AT, Bhoyar A, Daniels JP, Thangaratinam S, et al. Pulse oximetry screening for congenital heart defects in newborn infants (PulseOx): a test accuracy study. Lancet 2011; 378(9793): 785-94. https://doi.org/10.1016/S01406736(11)607 53-8

11. Hoffman JIE, Kaplan S. The incidence of congenital heart disease. American Journal of Cardiology 2002; 39(12): 1890-900. https://doi.org/10.1016/S07351097(02)018 86-7

12. Mitchell SC, Korones SB, Berendes HW. Congenital heart disease in 56,109 births. Incidence and natural history. Circulation 1971; 43: 323-32. https://doi.org/10.1161/01.CIR.43.3.323 PMid: 5102136

13. Wren C, Richmond S, Donaldson L. Presentation of congenital heart disease in infancy: implications for routine examination. Archives of Disease in Childhood Fetal and Neonatal Edition 1999; 80: 49-53.

https://doi.org/10.1136/fn.80.1.F49

PMid: 10325813 PMCid: PMC1720871

14. Lanker AM, Chowdhary J, Jeelani N, Jeelani S, Hassan AU. Effectiveness of pulse oximetry screening for congenital heart disease in asymptomatic new-borns. International Journal of Research in Medical Sciences 2014; 2(3): 1112-6. https://doi.org/10.5455/23206012.ijrms201 40894 
15. Mahle WT, Newburger JW, Matherne GP, Smith FC, et al. Role of pulse oximetry in examining newborns for congenital heart disease: a scientific statement from the American Heart Association and American Academy of Paediatrics. Circulation 2009; 124: 823-36.

https://doi.org/10.1161/CIRCULATIONA HA.109.192576

PMid: 19581492

16. Bakr AF, Habib HS. Combining pulse oximetry and clinical examination in screening for congenital heart disease. Paediatric Cardiology 2005; 26: 832-5. https://doi.org/10.1007/s00246-005-0981-9 PMid: 16088415

17. Warnes CA, Liberthson R, Danielson GK, Dore A, Harris L, Hoffman J, et al. Task force 1: the changing profile of congenital heart disease in adult life. Journal of the American College of Cardiology 2001; 37(5): 1170-5. https://doi.org/10.1016/S07351097(01)012 $72-4$

18. Van der Bom T, Zomer AC, Zwinderman $\mathrm{AH}$, Meijboom FJ, Bouma BJ, Mulder BJM. The changing epidemiology of congenital heart disease. Nature Reviews, Cardiology 2010; 8(1): 50-60.

https://doi.org/10.1038/nrcardio.2010.166

PMid: 21045784

19. Triedman JK, Newburger JW. Trends in congenital heart disease. Circulation 2016; 133: 2716-33. https://doi.org/10.1161/CIRCULATIONA HA. 116.023544

PMid: 27324366
20. Marelli AJ, Lonescu-ittu R, Mackie AS, Guo L, Dendukuri N, Kaouache M. Lifetime prevalence of congenital heart disease in the general population from 2000 to 2010 . Circulation 2014; 130: 749-56. https://doi.org/10.1161/CIRCULATIONA HA. 113.008396

PMid: 24944314

21. Bernier P-L, Stefanescu A, Samoukovic G, Tchervenkov CI. The challenge of congenital heart disease worldwide: epidemiologic and demographic facts. Seminars in Thoracic and Cardiovascular Surgery: Paediatric Cardiac Surgery Annual 2010; 13(1): 26-34. https://doi.org/10.1053/j.pcsu.2010.02.005 PMid: 20307858

22. Nazari P, Davoodi M, Faramarzi M, Bahadoram M, Dorestan N. Prevalence of congenital heart disease: A single centre experience in Southwestern Iran. Global Journal of Health Science 2016; 8(10): 28894.

https://doi.org/10.5539/gjhs.v8n10p288

PMid: 27302457

23. Reller MD, Strickland MJ, RieHieColarussoet T, Mahie WT, Correa A. Prevalence of congenital heart defects in metropolitan Atlanta, 1998-2005. Journal of Pediatrics 2008; 153(6): 807-13. https://doi.org/10.1016/j.jpeds.2008.05.059 PMid: 18657826 PMCid: PMC2613036 